\title{
Spinal cord arteriovenous malformations: a practical guide
}

\begin{abstract}
Spinal cord arteriovenous malformations are relatively rare pathological entities characterized by anomalous arteriovenous communication. Although uncommon, they are characterized by non-specific clinical presentation, ranging from mild general symptoms to even life-threatening events, such as subarachnoid or intramedullary haemorrhage, that usually results in delayed diagnosis and treatment. The purpose of this article is to briefly review the different types of spinal cord arteriovenous malformations providing an overview of the clinical, radiological and therapeutic features.
\end{abstract}

Keywords: spinal cord, arteriovenous malformations, arteriovenous fistulas
Volume 8 Issue 2 - 2018

\author{
Sergio Racchiusa, Marco Cavallaro, Marcello \\ Longo, Antonio Caragliano, Ugo Barbaro, \\ Karol Galletta, Sergio Lucio Vinci, Francesca \\ Granata \\ Department of Biomedical Sciences and Morphological and \\ Functional Imaging; University of Messina, Italy
}

Correspondence: Sergio Racchiusa, Department of Biomedical Sciences and Morphological and Functional Imaging; University of Messina, Policlinico “G. Martino" Via Consolare Valeria I, 98100, Messina, Italy, Email sergioracchiusa@gmail.com

Received: January 17, 2017 | Published: March 28, 2018

\section{Background}

Spinal cord arteriovenous malformations (SCAVMs) are a miscellaneous group of entities located within the vertebral canal, characterized by the abnormal communication between the arterial and the venous vessels. They represent around the $3-4 \%$ of all spinal cord mass lesions and can be broadly divided into two categories: arteriovenous malformations "sensu stricto" (AVMs), characterized by a network ("nidus") of abnormal vessels between the feeding arteries and the draining veins, and arteriovenous fistulas (AVFs), with a direct shunt between the artery and vein. ${ }^{1}$ The aim of this article is to briefly summarize the different types of spinal cord arteriovenous malformations, showing the clinical, radiological and therapeutic features. For the sake of brevity, we will not discuss other spinal vascular abnormalities, like aneurysms and neoplastic vascular lesions (hemangiomas, hemangioblastomas, cavernous malformations, etc.).

\section{Clinical presentation}

SCAVMs can exhibit various clinical manifestations, depending on their nature and location. The age at onset of symptoms is different between the two groups of arteriovenous lesions: most of AVFs typically appear in middle-age patients, while AVMs are generally diagnosed in childhood or early adulthood. ${ }^{2}$ Clinical onset can be sudden or gradual, ranging from mild general symptoms to debilitating and even life-threatening events.

The main pathophysiological mechanism responsible for symptoms is related to venous hypertension due to high arterial pressure transmitted to the venous system when a SCAMV is formed. The dilated veins can either compress the surrounding structures, thus causing myelopathy and/or radiculopathy, or rupture, with subsequent subarachnoid or intramedullary haemorrhage. ${ }^{1}$ A slow decline of sensorial and motor functions, until progressive chronic myelopathy, is the typical clinical feature of AVFs, whereas sudden-onset of symptoms due to haemorrhage or compression-induced myelopathy is the most common event in MAVs. ${ }^{3}$

\section{Diagnosis}

Diagnosis is based on clinical manifestations and radiological data. Magnetic Resonance Angiography (MRA) is usually the first neuroradiological exam performed, allowing the identification of SCAVMs and localizing the level of arterial feeder(s). ${ }^{4}$ Computed tomography angiography (CTA), due to its high spatial resolution, is also considered a valid alternative method. ${ }^{5}$ However, Digital Subtraction Angiography (DSA) remains the investigation of choice to study all SCAVMs features in order to establish the best treatment plan. ${ }^{6}$

\section{Classification}

A great number of different classification schemes have been proposed for spinal cord vascular malformations.

According to one of the most widely used classification system, proposed by Spetzler and collaborators in 2002, AVFs and AVMs can be subdivided into the following categories on the basis of anatomical and pathophysiological features: ${ }^{7}$ extradural AVF, intradural AVF (dorsal or ventral), extradural-intradural AVMs and intradural AVMs (subdivided into intramedullary and conus medullaris AVM).

\section{Extradural AVF (E-AVF)}

Extradural (or epidural) AVF are relatively uncommon malformations characterized by anomalous communication . between an extradural branch, usually of a radicular artery, and the epidural venous plexus.

According to Clarke et al., ${ }^{8}$ E-AVF can be classified, on the basis of their venous drainage patterns into:

i. E-AVFs with intradural/perimedullary drainage, typically diagnosed in the thoracolumbar and lumbar regions in patients around the sixth decade of life. 
ii. E-AVFs with pure extradural/paravertebral drainage, more frequently encountered in younger patients (around the third decade of life), with a predilection for the cervical and upper dorsal region. ${ }^{9}$

\section{Intradural AVF}

\section{Dorsal}

Intradural dorsal AVF (ID-AVFs), also referred as, among others, dural AVFs, angioma racemosum, type I AVFs, are the most common type of SCAMVs, occurring in $80 \%$ of cases, ${ }^{1}$ and more frequently involve the thoracic region. These fistulas represent an abnormal connection between one or more radiculomeningeal arteries and a radicular vein with retrograde drainage to the perimedullary leptomeningeal venous plexus. Typically these lesions are located in the dura mater around the sensory ganglion of the proximal nerve root. They can be subclassified into lesion with a single feeding artery (type A) and lesions with multiple feeding arterial vessels (type B). ${ }^{7}$

\section{Ventral}

Ventral AVFs (IV-AVFs), also known as perimedullary AVFs or type IV AVFs, are characterized by an intradural direct connection between a radiculomedullary arterial feeder from the anterior or posterior spinal artery and a superficial perimedullary vein, and are located superficially on the spinal cord. According to Anson and Spetzler classification, ${ }^{10}$ IV-AVFs can be differentiated on the basis of the size and flow of the vascular connection into three groups: type A (single feeder, slow flow), type B (multiple feeders, high flow) and type $\mathrm{C}$ (giant, multiple feeders) fistulas, with several differences regarding aetiology, age onset, symptomatology and therapeutic approach. ${ }^{11}$

\section{Extradural-Intradural AVM (EI-AVM)}

These exceptionally rare and complex lesions, also called juvenile, metameric or type III malformations, present highly variable arterial and venous support and, even though they are usually intramedullary, they may have extramedullary and paraspinal extension, involving vertebrae, spinal nerve roots, soft tissues and skin. ${ }^{12}$ Among all the SCAVMs, they present at the youngest age, have the highest rate of associated aneurysms (almost 50\% of patients), which represent an additional risk factor for hemorrhage onset, ${ }^{13}$ and are the most difficult to treat, given their complex nature. Endovascular embolization and surgery can be used and, although complete obliterations have been reported, the primary aim of intervention is usually palliative. ${ }^{3}$

\section{Intradural AVM (I-AVM)}

\section{Intramedullary}

Intramedulllary AVMs, also referred as glomus or type II AVMs, are rare lesions, supplied by a radiculomedullary and/or radiculopial artery draining into the coronal venous plexus around the cord. Generally, they have multiple feeding arteries that originate from both the anterior and posterior system ${ }^{14}$ and present associated aneurysms in $30 \%$ of cases. Although considered very challenging for the intramedullary location and complex angioarchitecture of the lesion, treatment is generally required in order to reduce symptoms and prevent the risk of haemorrhage. ${ }^{15}$

\section{Conus medullaris}

Conus medullaris AVMs are a specific type of AVMs located in the conus medullaris or cauda equine and may even extend along the entire filum terminale. In consideration of the unique location and particular anatomy of these lesions, they often produce radiculopathy and myelopathy at the same time, with both upper and motor neuron symptoms. ${ }^{12}$

\section{Treatment}

Therapeutic options for SCAVMs comprise endovascular embolization and surgical treatment, depending on the hemodynamics of the lesion, its site and angioarchitecture, and a multidisciplinary approach is essential in order to plan the best management. ${ }^{3}$ Endovascular embolization generally represents the first-line choice for almost all SCAVMs. However, surgery still plays a key role, particularly for AVFs. For intradural dorsal AVFs - the most common SCAVMs - surgical ligation should be performed according to the characteristics of the fistula, patient's conditions and whenever endovascular embolization fails. ${ }^{14}$

In intradural ventral AVFs, the choice of treatment is strongly dependent on the subtype of fistula, with surgery being preferred in type A lesions and endovascular embolization in type B and C. For conus medullaris AVMs, in consideration of their complex nature, a multimodality approach with combined endovascular and microsurgical treatment has shown in some series the better results. ${ }^{16}$

\section{Acknowledgements}

None.

\section{Conflict of interest}

The authors declare no conflict of interest.

\section{Funding}

This research did not receive any specific grant from funding agencies in the public, commercial, or not-for-profit sectors.

\section{References}

1. Ozpinar A, Weiner GM, Ducruet AF. Epidemiology, clinical presentation, diagnostic evaluation, and prognosis of spinal arteriovenous malformations. Handb Clin Neurol. 2017;143:145-152.

2. Jeng Y, Chen DY, Hsu HL, et al. Spinal dural arteriovenous fistula: imaging features and its mimics. Korean J Radiol. 2015;16(5):1119-31.

3. Patsalides A, Knopman J, Santillan A, et al. Endovascular treatment of spinal arteriovenous lesions: beyond the dural fistula. AJNR Am J Neuroradiol. 2011;32(5):798-808.

4. Mull M, Nijenhuis RJ, Backes WH, et al. Value and limitations of contrastenhanced MR angiography in spinal arteriovenous malformations and dural arteriovenous fistulas. AJNR Am J Neuroradiol. 2007;28(7):1249-58.

5. Lai PH, Weng MJ, Lee KW, et al. Multidetector CT angiography in diagnosing type I and type IVA spinal vascular malformations. AJNR Am J Neuroradiol. 2006;27(4):813-7.

6. Krings T, Geibprasert S. Spinal dural arteriovenous fistulas. AJNR Am J Neuroradiol. 2009;30(4):639-48.

7. Spetzler RF, Detwiler PW, Riina HA, et al. Modified classification of spinal 
cord vascular lesions. J Neurosurg. 2002;96(2 Suppl):145-56.

8. Clarke MJ, Patrick TA, White JB, et al. Spinal extradural arteriovenous malformations with parenchymal drainage: venous drainage variability and implications in clinical manifestations. Neurosurg Focus. 2009;26(1):E5.

9. Brinjikji W, Yin R, Nasr DM, et al. Spinal epidural arteriovenous fistulas. $J$ Neuro Intervent Surg. 2016;8(12):1-7.

10. Anson J, Spetzler R. Classification of spinal arteriovenous malformations and implications for treatment. BNI Q 1992;8:2-8.

11. Gross BA, Du R. Spinal pial (type IV) arteriovenous fistulae: a systematic pooled analysis of demographics, hemorrhage risk, and treatment results. Neurosurgery. 2013;73(1):141-51.

12. Kim LJ, Spetzler RF. Classification and surgical management of spinal arteriovenous lesions: arteriovenous fistulae and arteriovenous malformations. Neurosurgery. 2006;59(5 Suppl 3):S195-201.
13. Gross BA, Du R. Spinal juvenile (Type III) extradural-intradural arteriovenous malformations. J Neurosurg Spine. 2014;20(4):452-8.

14. Krings T. Vascular Malformations of the Spine and Spinal Cord. Clin Neuroradiol. 2010;20(1):5-24.

15. Daou B, Atallah E, Al-Saiegh F, et al. Spinal Glomus Arteriovenous Malformation Manifesting with a Subarachnoid Hemorrhage. World Neurosurg. 2017;98:874.e1-874.e6.

16. Wilson DA, Abla AA, Uschold TD, et al. Multimodality treatment of conus medullaris arteriovenous malformations: 2 decades of experience with combined endovascular and microsurgical treatments. Neurosurgery. 2012;71(1):100-108. 